\title{
Milk quality assurance for paratuberculosis: simulation of within-herd infection dynamics and economics
}

\author{
Maarten F. WEBER ${ }^{1 *}$, Mirjam NIELEN ${ }^{2}$, Annet G.J. VelthUis ${ }^{3}$, \\ Herman J.W. VAN ROERMUND ${ }^{4}$ \\ ${ }^{1}$ Animal Health Service, PO Box 9, 7400 AA Deventer, The Netherlands \\ ${ }^{2}$ Utrecht University, PO Box 80151, 3508 TD Utrecht, The Netherlands \\ ${ }^{3}$ Business Economics, Wageningen University, Hollandseweg 1, $6706 \mathrm{KN}$, Wageningen, The Netherlands \\ ${ }^{4}$ Animal Sciences Group, PO Box 65, 8200 AB Lelystad, The Netherlands
}

(Received 12 February 2007; accepted 8 October 2007)

\begin{abstract}
A bulk milk quality assurance programme for Mycobacterium avium subsp. paratuberculosis (Map) in dairy herds was simulated with a stochastic simulation model (JohneSSim). The aim of this study was to evaluate the epidemiological and economic effects of preventive management measures and various test schemes in a simulated population of closed Dutch dairy herds over a 20 -year period. Herds were certified as 'low-Map bulk milk' if, with a certain probability, the concentration of Map in bulk milk did not exceed a maximum acceptable concentration of $10^{3}$ Map organisms per litre (based on pasteurisation studies). The programme started with an initial assessment; test-negative herds entered a surveillance procedure and test-positive herds a control procedure. The simulations showed that herd examinations by ELISA for the initial assessment, surveillance and control procedures effectively ensure the quality of 'lowMap bulk milk': $>75 \%$ of simulated herds were certified and $>96 \%$ of certified herds produced bulk milk with $<10^{3} \mathrm{Map} / \mathrm{L}$ if the initial herd-level prevalence was $30 \%$. Preventive management measures only had a minor effect on bulk milk quality of certified herds. Culling based on biennial faecal culture was more effective than culling based on annual ELISA. Average total discounted costs for 20-year participation in a programme consisting of initial assessment by ELISA, surveillance by biennial ELISA and control by biennial faecal culture were $€ 16 \times 10^{3}$ per herd. In conclusion, this study shows that a bulk milk quality assurance programme for closed Dutch dairy herds is feasible and provides information on the cost-effectiveness of different programmes. The concepts of this study equally apply to other countries because mechanisms of paratuberculosis infection, disease, and testing are comparable in other dairy cattle populations.
\end{abstract}

dairy cattle / milk / paratuberculosis / stochastic simulation model / quality assurance programme

\section{INTRODUCTION}

Mycobacterium avium subsp. paratuberculosis (Map) infections in cattle are of concern to the dairy industry due to the as-yetunresolved issue of its potential role in Crohn's disease in humans ${ }^{1,2}$ [5]. Milk is a possible

\footnotetext{
* Corresponding author: m.weber@gddeventer.com ${ }^{1}$ EU, Possible links between Crohn's disease and Paratuberculosis, Report, Scientific Committee on Animal Health and Animal Welfare, European Commission, 76 pp. [on line] (2000) http://europa.eu.int/comm/food/fs/sc/scah/ out38_en.pdf [consulted 21 December 2004].

${ }^{2}$ Herrewegh A.A.P.M., Roholl P.J.M., Overduin P., van der Giessen J.W.B., van Soolingen D., Is there
}

vehicle of transmission of Map to humans, because Map has been detected in raw milk [3, $10,14,28,33,36]$ and might not be effectively inactivated by pasteurisation $[3,9,12-16,24$, 34]. A milk quality assurance programme for paratuberculosis in dairy herds might reduce the potential risk of transmission of Map to humans through consumption of dairy products.

evidence for a link between Crohn's disease and exposure to Mycobacterium avium ssp. paratuberculosis? A review of current literature, RIVM report 230086001/2004, 81 pp. [on line] (2004) http:// www.rivm.nl/bibliotheek/rapporten/230086001.html [consulted 3 July 2007]. 
Certification-and-surveillance programmes for supposedly Map-free herds and control programmes for Map-infected herds have been developed in several countries, such as the $\mathrm{USA}^{3}$, Australia, and the Netherlands [4, 20,23]. These certificationand-surveillance and control programmes generally aim at a low-risk trade of cattle and elimination of Map. Therefore, these programmes are inherently expensive and participation is often restricted to a minority of herds. For example, in the certificationand-surveillance programme that has been in place in the Netherlands since 1998, five negative annual herd examinations by different tests (including serology and faecal culture) are required to obtain 'Map-free' status [4]. By July 2005, only 473 of approximately 23000 Dutch dairy herds had obtained this 'Map-free' status. However, the goal of a milk quality assurance programme is to reduce the concentration of Map in bulk milk rather than eradication of Map. Herds in a milk quality assurance programme can be certified as 'lowMap bulk milk' if, with a certain probability, the concentration of Map in bulk milk does not exceed a pre-set maximum acceptable concentration. This does not necessarily mean that the herd is free of Map. Thus, such a milk quality assurance programme might possibly be run at considerable lower costs than a programme aiming at low-risk trade of cattle and elimination of Map.

A milk quality assurance programme would start with an initial assessment of each herd; test-negative herds enter a surveillance procedure and test-positive herds enter a control procedure. Herds subsequently testing positive in the surveillance procedure shift to the control procedure. The control procedure aims to decrease the concentration of Map in milk by suppression of the infection in the herds, such that the milk quality can be guaranteed and the herd can shift to the surveillance procedure. Test-negative herds in the surveillance procedure are assigned the 'low-Map

\footnotetext{
${ }^{3}$ Bulaga L.L., Collins, M.T., U.S. voluntary Johne's disease herd status program for cattle, Proc. 6th Int. Coll. Paratuberculosis, Melbourne, 1999, pp. 39-47.
}

bulk milk' status. However, various alternative test schemes for the initial assessment, surveillance and control procedures are available, and it was unknown which test schemes would be most attractive. Furthermore, preventive management measures are important in programmes aiming at low-risk trade of cattle or elimination of Map [17,37], but their cost-effectiveness in a milk quality assurance programme was unknown. Therefore, the aim of this study was to simulate a milk quality assurance programme in a population of closed Dutch dairy herds to evaluate the epidemiological effects and economic consequences of various alternative test schemes and preventive management measures.

\section{MATERIALS AND METHODS}

\subsection{The JohneSSim model}

The JohneSSim model is a stochastic and dynamic simulation model that simulates (a) herd dynamics, (b) disease dynamics within the herd, (c) the control of Johne's disease, and (d) the economic consequences at the herd level. The model and its use to study certification-and-surveillance programmes have been described in detail $[17,37]$.

In short, the model simulates a period of 20 years with, at the background, time steps of 6 months and generates output-data with time steps of 12 months. The herd dynamics of a typical Dutch dairy herd are simulated, including calves and replacement heifers. All animals in the herd have various attributes (such as parity, stage of infection, month in lactation, and milk production). The model contains probability distributions for uncertain events (such as replacement, infection, progression of the stage of infection, testing). Both voluntary culling and involuntary culling are considered. The percentage of cows culled involuntarily is specified per lactation. Voluntary culling is based on the retention pay-off (RPO), i.e. the expected profit from trying to keep the animal until its optimal life-span is complete compared with immediate replacement, taking into account the risk of involuntary premature removal [18]. Cattle with the lowest RPO are culled until the number of adults is equal to the intended maximum number of adults in the herd.

In the model, five infection routes are considered: (1) intra-uterine infections, (2) infections at birth, (3) infections due to drinking colostrum, (4) infections due to drinking whole milk, and (5) infections due to environmental contamination with 


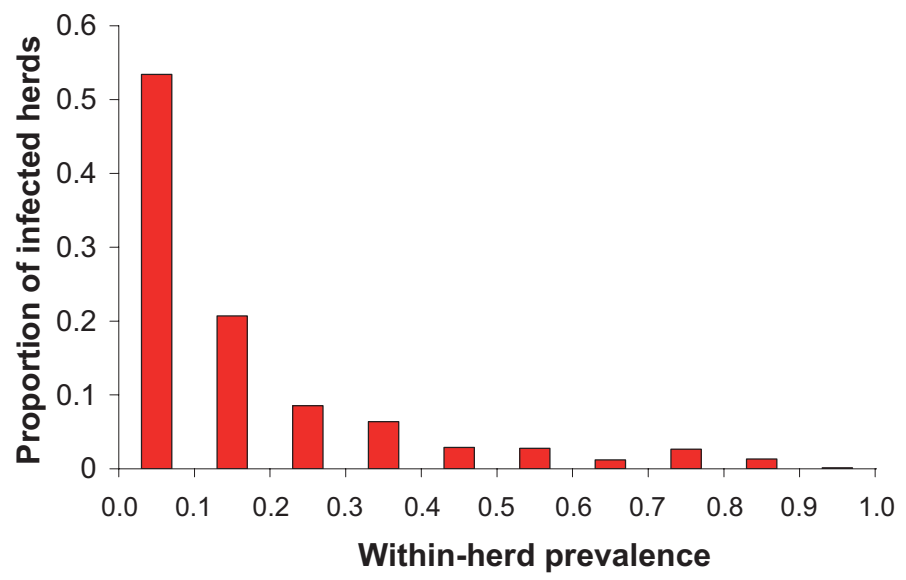

Figure 1. Assumed distribution of within-herd true prevalence of Map in infected Dutch dairy herds at the start of simulations. Thirty percent of herds were assumed to be infected, based on a recent study in the Netherlands ${ }^{5}$.

Map. Six stages are distinguished in the infectionand-disease process in individual cattle: (1) susceptible (i.e. uninfected, $<1$ year of age), (2) non-susceptible (i.e. uninfected, $\geqslant 1$ year of age), (3) latent infected, (4) lowly infectious, (5) highly infectious, and (6) clinical disease. The progress of the infection-and-disease process in infected cattle is influenced by the age at infection.

The probability distributions for uncertain events are used for random sampling. Repeated runs of the model provide insight into the variation in outcomes at the farm level. Results at a higher aggregation level (e.g. national level) are obtained by simulating different types of dairy herds and aggregating the results according to their relative abundance.

All costs and losses are discounted, i.e. their net present values are calculated for a 10 -year or 20 -year period. Costs of culling an animal are estimated by its RPO.

\subsection{Assumptions in the JohneSSim model for present study}

Preventive management in the simulated herds was set to reflect the distribution of management practices in the Dutch dairy industry ('background' management). To represent the differences between preventive management on individual dairy farms, eight different herd risk-profiles were defined and simulated separately [17]. Both infected and noninfected herds are simulated. Therefore, in total 16 herd types were simulated separately ( 8 risk profiles $\times 2$ infection classes, infected and noninfected). The results of these herd types were aggregated according to their relative abundance in the Dutch dairy population to obtain results at the national level. In total, the aggregation of all herd types consisted of 10500 iterations (including 200 to 1944 iterations per herd type).

All herds were assumed to be closed (i.e. no purchase of animals and no new introductions of Map). Herd-size was assumed to be initially 65 adults $(\geqslant 2$ year), and to increase by $5 \%$ per annum. Eighty to $100 \%$ of heifer calves were raised in the herd, while a surplus of heifers was sold shortly before first calving. Mean annual milk production was $8000 \mathrm{~kg}$. The assumed distribution of the initial within-herd true prevalence in infected herds was based on analyses of Dutch seroprevalence data [26] using a Bayesian model [31] with assumptions on test characteristics based on a Dutch validation study ${ }^{4}$ and is shown in Figure 1. Initial herd-level true prevalence was assumed to be 0.30 , based on a recent study in the Netherlands ${ }^{5}$. Costs of participation in the quality assurance programme and costs of preventive management measures were updated for this study (Tab. I and II). Economic

\footnotetext{
${ }^{4}$ Van Maanen C., Koster C., van Veen B., Kalis C.H.J., Collins M.T., Validation of Mycobacterium avium subsp. paratuberculosis antibody detecting ELISA's, in: Juste R.A., Geijo M.V., Garrido J.M. (Eds.), Proc. 7th Int. Coll. Paratuberculosis, Bilbao, 2002, p. 182.

${ }^{5}$ Van Weering, Personal communication, 2004.
} 
Table I. Variable costs (Euro) of participation in the bulk milk quality assurance programme. Additional annual subscription costs were $€ 90$. Value added tax (VAT) was added to these costs $(6 \%$ on costs of subscription and laboratory tests and $19 \%$ on other costs).

\begin{tabular}{|c|c|c|c|c|}
\hline \multirow[t]{2}{*}{ Test / action } & \multirow{2}{*}{$\begin{array}{c}\text { Costs } \\
\text { veterinarian } 1\end{array}$} & \multirow{2}{*}{$\begin{array}{l}\text { Transport costs } \\
\text { per submission }\end{array}$} & \multicolumn{2}{|r|}{ Laboratory costs ${ }^{2}$} \\
\hline & & & per submission & per test \\
\hline Veterinarians' visit & 22 & & & \\
\hline $\mathrm{IFC}^{3}$ & 2.75 per animal & 10 & 7.80 & 30.00 per animal \\
\hline $\mathrm{PFC}^{4}$ & 3.25 per animal & 10 & 7.80 & 37.50 per pool (max. 5 animals) \\
\hline ELISA & 2.75 per animal & 10 & 7.80 & 6.15 per animal \\
\hline
\end{tabular}

${ }^{1}$ Based on rates charged in 2004 by a convenience sample of veterinary practices.

${ }^{2}$ Based on rates charged in 2004 by the Animal Health Service.

${ }^{3}$ IFC $=$ individual faecal culture.

${ }^{4} \mathrm{PFC}=$ pooled faecal culture.

assumptions on losses by paratuberculosis and on the costs of culling of test-positive cattle were also updated (Tab. II). All costs were discounted at a real interest rate (approximated by interest rate minus inflation rate) of $5 \%$ per year. Assumptions on test characteristics are shown in Table III. Assumptions on effectiveness of additional preventive management measures, imposed on the "background' management, were based on the opinions of an expert panel [17]. By default, effective separation of young stock from adult cattle was assumed to reduce the number of effective cow-calf contacts through faecal contamination of the environment by $90 \%$. Details of assumptions made for the present study are available online in the Appendix at http://www.vetres.org.

\subsection{Shedding of Map in milk}

The assumptions made on shedding of Map in milk depending on the stage of infection of an animal are shown in Table IV. These assumptions were based on the available quantitative data on direct shedding of Map in milk ${ }^{6,7}[3,10,33,36]$, faecal contamination of milk [32], shedding of Map in fae$\operatorname{ces}^{8}[6,11,27,29,35]$, and the concentration of Map in bulk milk [15]. In the present study, the concentration of Map in bulk milk was approximated by the average of the concentration of Map in milk of

\footnotetext{
${ }^{6}$ McDonald W.L., O’Riley K.J., Schroen C.J., Condron R.J., Heat inactivation of Mycobacterium avium subsp. Paratuberculosis, in: Juste R.A., Geijo M.V., Garrido J.M. (Eds.), Proc. 7th Int. Coll. Paratuberculosis, Bilbao, 2002, pp. 312-316.

${ }^{7}$ Rademaker, Personal communication, 2004.

${ }^{8}$ Stehman, Personal communication, 2004.
}

each dairy cow in the herd. This approximation was justified because faecal contamination is the predominant source of Map in milk (Tab. IV) and is not restricted to a cow's own milk - meaning that variation in milk yield between cows can be ignored.

\subsection{Acceptable concentration of Map-organisms in milk}

The concentration of Map organisms in on-farm bulk milk that can be considered acceptable is unknown. No quantitative data on human exposure to Map (either alive or dead Map organisms) are available and the probability of human disease due to exposure is unknown. Therefore, in the present study, we assumed that no viable Map organisms should be present after commercial pasteurisation. Map can survive high-temperature short-time (HTST) pasteurisation when the initial organism concentration is $\geqslant 10^{4}$ cells per litre of milk $[16,34]$. To our knowledge, no study indicated that Map could survive HTST pasteurisation when the initial organism concentration is $\leqslant 10^{3}$ cells per litre. Moreover, the inactivation of Map achieved by pasteurisation conditions used by the Dutch dairy industry has been estimated at $>4.2 \log _{10}$ to $>7.1 \log _{10}$ [30]. Therefore, in this study, we considered a concentration of Map organisms in milk less than $10^{3}$ per litre acceptable.

\subsection{Bulk milk quality assurance programmes}

In our simulations, certified 'low-Map bulk milk' dairy herds were assigned a 'green' status, while other dairy herds were assigned a 'red' status. Thus, 'green' herds were herds with a high confidence that the concentration of Map in bulk 


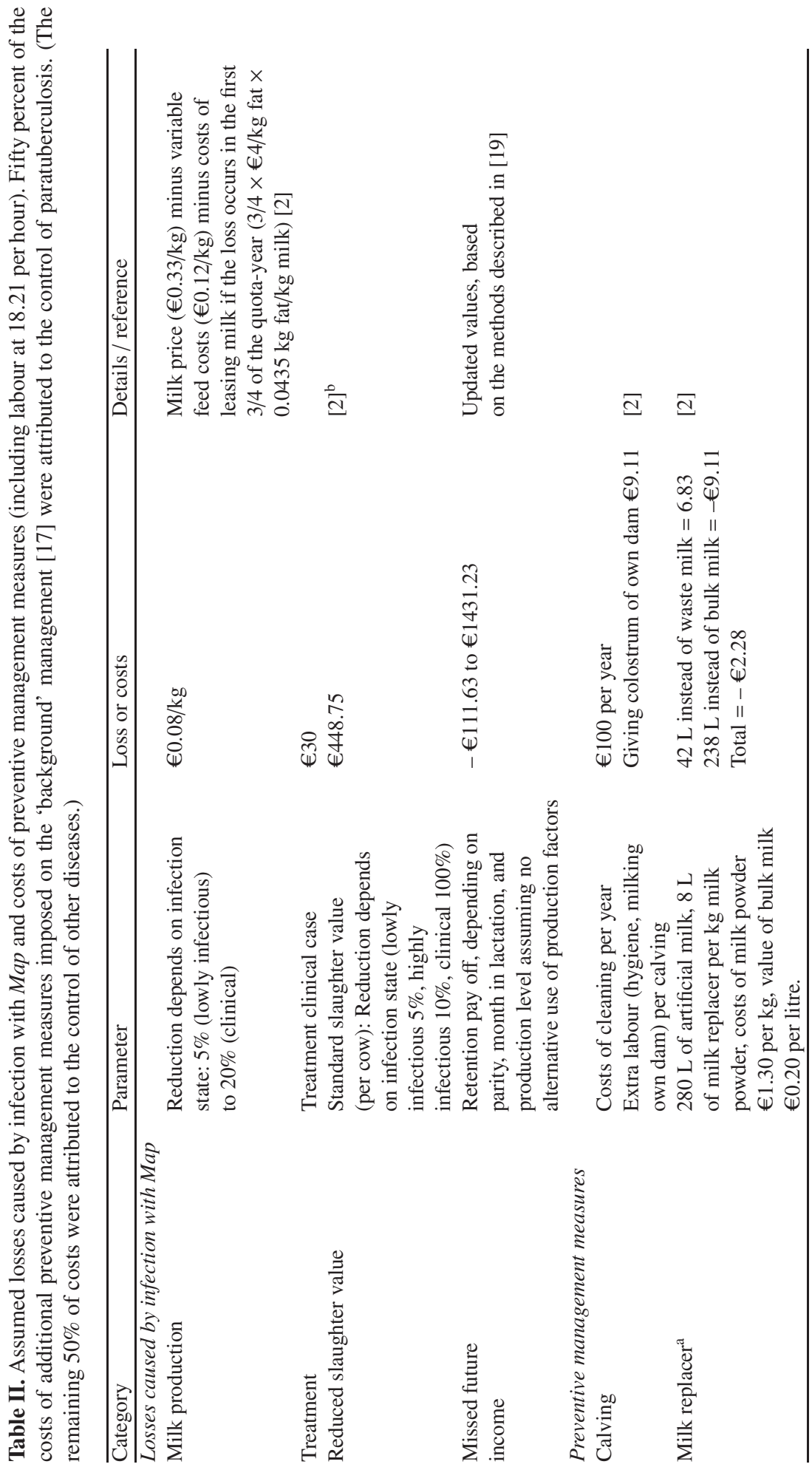




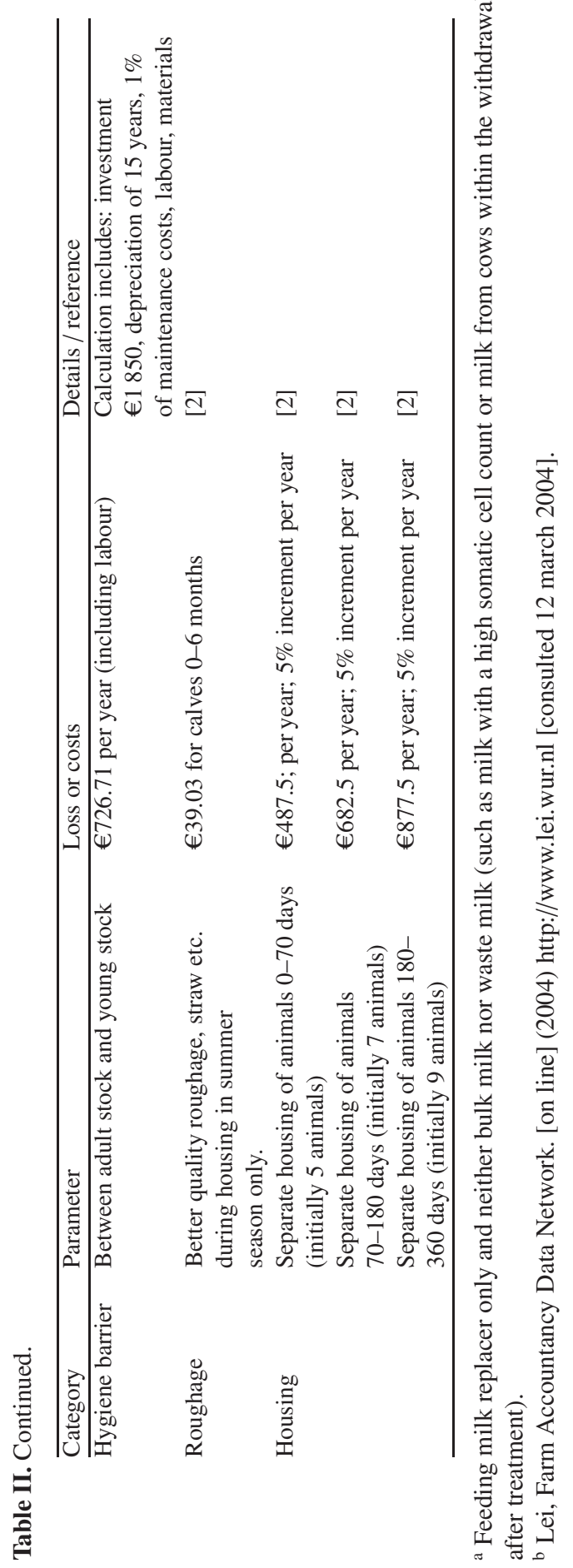


Table III. Assumptions on sensitivity (Se) and specificity ( $\mathrm{Sp}$ ) of individual faecal culture (IFC), pooled faecal culture (PFC) and ELISA.

\begin{tabular}{lllll}
\hline & $\begin{array}{l}\text { Stage of infection } \\
\text { of animal }\end{array}$ & IFC & PFC & ELISA \\
\hline Se & Latent infected & 0 & 0 & 0.01 \\
& Lowly infectious & 0.40 & 0.36 & 0.10 \\
& Highly infectious & 0.95 & 0.95 & 0.60 \\
& Clinical disease & 0.90 & 0.90 & 0.80 \\
Sp & Not infected & 1 & 1 & $0.997^{4}$ \\
\hline
\end{tabular}

milk was $<10^{3} / \mathrm{L}$. The initial assessment of herds was done two years after the start of the simulations, because it was anticipated that a bulk milk quality assurance programme would not be initiated within two years after the seroprevalence study ${ }^{9}$ on which the assumptions on the herd-level prevalence were based. At the initial assessment, test negative herds were assigned a 'green' status and test-positive herds a 'red' status. Thereafter, 'green' herds were regularly monitored in a surveillance procedure, with herds testing positive being moved to the pool of 'red' herds. A control procedure was applied to 'red' herds; test positive cattle and their last-born offspring were culled.

Various alternative test schemes for the initial assessment, surveillance procedure and control procedure were simulated (Table V, schemes A to D). Test schemes were based on herd examinations by serology (ELISA), individual faecal culture (IFC) [21] or pooled faecal culture (PFC) [22]. For each test scheme, the number of negative herd examinations required for a 'red' herd to move to the pool of 'green' herds was determined by the confidence that the concentration of Map in bulk milk was $<10^{3} / \mathrm{L}$. A test-negative 'red' herd became 'green' if this confidence was equivalent to the probability for a 'green' herd immediately after the initial assessment procedure to have $<10^{3} \mathrm{Map} / \mathrm{L}$. For each test scheme, the number of negative herd examinations required was calculated both with and without additional preventive management measures imposed by all herds on their 'background' management.

For comparison, the test scheme of the Dutch 'Map-free' certification-and-surveillance programme was simulated as well (Tab. V, scheme $\mathrm{E}$ ). The aim of this programme is to enable low-risk trade of cattle between herds. The initial assessment of this programme consists of five annual herd examinations (the first herd exami-

\footnotetext{
${ }^{9}$ Van Weering, Personal communication, 2004.
}

nation by ELISA, the second to fifth examination by PFC). Surveillance is done by biennial herd examination by PFC. ELISA-positive animals and culture-positive pools are re-tested by IFC. In the programme, various options are available for control of Map in test-positive herds. However, in this study, we simulated that these 'red' herds were tested annually by IFC. With scheme E, a 'red' herd only became 'green' after five negative annual herd examinations (by IFC or PFC), in line with the regulations of the Dutch 'Map-free' certification-and-surveillance programme.

All programmes were simulated with and without additional preventive management measures imposed by all participating herds (regardless of 'red' or 'green' status) on their 'background' management right from the start of the simulations. The following combined preventive measures were applied: improved hygiene around birth, colostrum from own dam only, feeding of artificial milk replacer only, and effective separation of young stock from adult cows for the first year after birth.

\subsection{Model output}

In the present study, relevant herd-specific predicted outcomes over time were the within-herd true- and test-prevalence, the concentration of Map in bulk milk, losses caused by paratuberculosis and costs spent on the milk quality assurance programme (including herd examinations, subscription costs, additional preventive management measures, and culling of infected animals). Losses caused by paratuberculosis did not include a possible lower milk price due to potential consumer concerns. Relevant outcomes over time on the national herd level included the proportion of 'green' dairy herds (as a proportion of all dairy herds), the average concentration of Map in bulk milk from 'green' herds, the proportion of 'green' herds with $<10^{3}$ Map organisms per litre of bulk milk (as a proportion of all 'green' herds), total national losses due to paratuberculosis and total national costs spent on the bulk milk quality assurance programme.

\subsection{Sensitivity analyses}

The influence of various input parameters on the study results was analysed, by changing one parameter at a time. These analyses were performed with test scheme D (Tab. V), with or without additional preventive management measures taken in all herds. The following parameter changes were made: (1) The default numbers of Map bacteria 
Table IV. Assumed concentration of Map-bacteria in milk of individual adult cattle for each stage of the infection-and-disease process (Total Map in milk = direct shedding + faecal contamination $\times$ Map in faeces. Faecal contamination was assumed to be $0.04 \mathrm{~g} /$ litre of milk). The concentration of Map in bulk milk was approximated by the average concentration of Map in milk of all individual cattle in the herd.

\begin{tabular}{lcccc}
\hline Stage & $\begin{array}{c}\text { Proportion of } \\
\text { animals } \\
\text { within each stage }\end{array}$ & $\begin{array}{c}\text { Direct shedding of } \\
\text { Map in milk } \\
\text { (organisms per litre) }\end{array}$ & $\begin{array}{c}\text { Map in faeces } \\
\text { (organisms per gram) }\end{array}$ & $\begin{array}{c}\text { Total Map in milk } \\
\text { (organisms per litre) }\end{array}$ \\
\hline Latent infected & 0.8 & 0 & 0 & 0 \\
Lowly infectious & 0.2 & 0 & 0 & 0 \\
Highly infectious & 0.6 & 0 & $10^{2}$ & 4 \\
& 0.24 & $10^{2}$ & $10^{2}$ & $1.04 \times 10^{2}$ \\
Clinical disease & 0.16 & $10^{2}$ & $10^{4}$ & $5 \times 10^{2}$ \\
\hline
\end{tabular}

Table V. Simulated test schemes for initial assessment, surveillance (in 'green' herds) and control (in 'red' herds) procedures. In the initial assessment and surveillance procedure, a positive ELISA result was confirmed by individual faecal culture (IFC); IFC positive cattle and their lastborn calf were culled. In the control procedure, all ELISA or IFC positive cattle were culled.

\begin{tabular}{|c|c|c|c|c|c|c|c|c|}
\hline \multirow[t]{2}{*}{ Scheme } & \multicolumn{2}{|c|}{ Initial assessment $t^{a}$} & \multicolumn{3}{|c|}{$\begin{array}{c}\text { Surveillance } \\
\text { (in 'green' herds) }\end{array}$} & \multicolumn{3}{|c|}{$\begin{array}{c}\text { Control } \\
\text { (in 'red' herds) }\end{array}$} \\
\hline & Test & Animals & Test & Interval & Animals & Test & Interval & Animals \\
\hline$\overline{\mathrm{A}}$ & ELISA & $\mathrm{All}, \geqslant 3 \mathrm{yr}$ & ELISA & $1 \mathrm{yr}$ & $\mathrm{All}, \geqslant 3 \mathrm{yr}$ & ELISA & $1 \mathrm{yr}$ & $\mathrm{All}, \geqslant 3 \mathrm{yr}$ \\
\hline B & ELISA & $\mathrm{All}, \geqslant 3 \mathrm{yr}$ & ELISA & $1 \mathrm{yr}$ & $\mathrm{All}, \geqslant 3 \mathrm{yr}$ & IFC & $2 \mathrm{yr}$ & $\mathrm{All}, \geqslant 2 \mathrm{yr}$ \\
\hline $\mathrm{C}$ & ELISA & $\mathrm{All}, \geqslant 3 \mathrm{yr}$ & ELISA & $2 \mathrm{yr}$ & $\mathrm{All}, \geqslant 3 \mathrm{yr}$ & ELISA & $1 \mathrm{yr}$ & $\mathrm{All}, \geqslant 3 \mathrm{yr}$ \\
\hline D & ELISA & $\mathrm{All}, \geqslant 3 \mathrm{yr}$ & ELISA & $2 \mathrm{yr}$ & $\mathrm{All}, \geqslant 3 \mathrm{yr}$ & IFC & $2 \mathrm{yr}$ & $\mathrm{All}, \geqslant 2 \mathrm{yr}$ \\
\hline $\mathrm{E}^{\mathrm{b}}$ & $\begin{array}{l}\text { ELISA / } \\
\text { PFC }^{\mathrm{c}}\end{array}$ & $\begin{array}{l}\mathrm{All}, \geqslant 3 \mathrm{yr} / \\
\mathrm{All}, \geqslant 2 \mathrm{yr}\end{array}$ & PFC & $2 \mathrm{yr}$ & $\mathrm{All}, \geqslant 2 \mathrm{yr}$ & IFC $^{\mathrm{d}}$ & $1 \mathrm{yr}$ & $\mathrm{All}, \geqslant 2 \mathrm{yr}$ \\
\hline
\end{tabular}

${ }^{a}$ The initial assessment was done by a single herd examination (except in scheme E).

b Scheme E is the (current) test scheme for the 'Map-free' certification-and-surveillance programme for Dutch dairy herds.

${ }^{c}$ The initial assessment of scheme E consists of five annual herd examinations (the first herd examination by ELISA followed by IFC of ELISA-positive animals; the 2nd through 5th examination by pooled faecal culture (PFC) followed by IFC of positive pools).

${ }^{\mathrm{d}}$ In case of a negative herd-examination by IFC in a 'red' herd, a further four negative annual herd examinations by PFC (including all animals $\geqslant 2$ yr of age) are required before the herd is certified as 'Map-free'.

in milk (Tab. IV, last column) were multiplied by $10^{6}$ - even though such high concentrations of Map in milk are probably not biologically plausible. For example, clinically diseased animals then shed $4 \times 10^{13} \mathrm{Map} / \mathrm{L}$ of milk (instead of the default value of $4 \times 10^{7} \mathrm{Map} / \mathrm{L}$, Tab. IV). (2) The reduction of the effective cow-calf contacts through the environment by additional preventive management measures was changed from $90 \%$ (default value) to $50 \%$. (3) The default sensitivities of both the ELISA and IFC for each stage of the infection (Tab. III) were multiplied by 0.75 . (4) The number of negative herd-examinations required for a 'red' herd to become 'green' (by default two negative herd examinations by IFC, see Results) was changed to only one negative herd-examination. (5) By default, the initial herd-level true prevalence was 0.30 , based on a recent seroprevalence study ${ }^{10}$. However, in a previous seroprevalence study the herd-level true prevalence was estimated at 0.31 to 0.71 [26].

\footnotetext{
${ }^{10}$ Van Weering, Personal communication.
} 


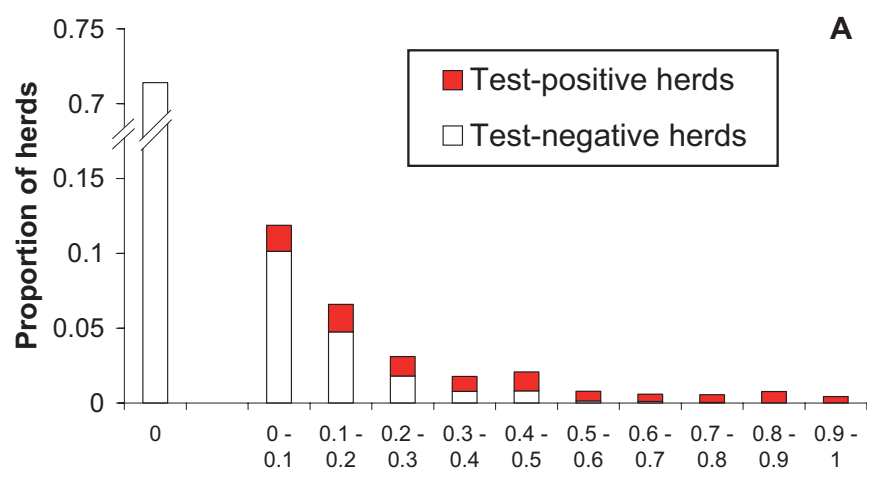

Within-herd true prevalence (adults)

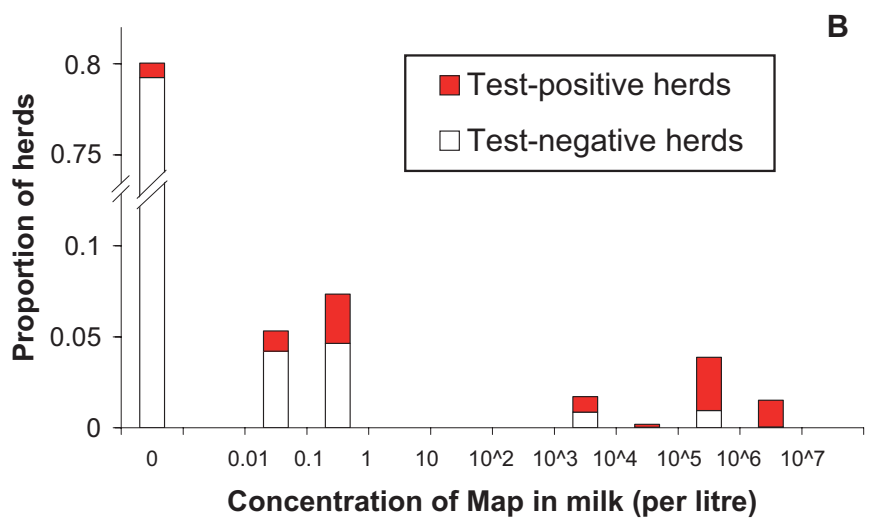

Figure 2. Estimated within-herd prevalence in adult cattle (A) and estimated concentration of Map organisms in bulk milk (B) immediately after initial assessment (and prior to culling of any test-positive cattle) in simulated herds that were test-positive ('red') and test-negative ('green') at the initial assessment by ELISA of all cattle $\geqslant 3$ years of age (test schemes A to D).

Therefore, in this sensitivity analysis, the herd-level true prevalence was changed from 0.30 to 0.70 .

\subsection{Statistical analyses}

The proportions of dairy herds certified as 'green' (as a proportion of all dairy herds) by different test schemes were compared by Pearson $\chi^{2}$. If an overall $\chi^{2}$ was significant then each alternative scheme was compared individually with scheme E (i.e. the Dutch certification-andsurveillance scheme for 'Map-free' herds, Tab. V) by Yate continuity corrected $\chi_{\mathrm{cc}}^{2}$, using Bonferroni correction of $p$ to adjust for multiple comparisons [1]. Cumulative discounted costs of different test schemes plus cumulative discounted losses caused by paratuberculosis were compared using the Kruskal-Wallis rank sum test (adjusted for ties). If significant differences were found, then each alternative test scheme was individually compared with scheme E using the Mann-Whitney test (adjusted for ties), with Bonferroni correction of $p$. In all tests, significance was declared at $p \leqslant 0.05$ (twosided).

\section{RESULTS}

\subsection{Simulated bulk milk quality assurance programmes}

At the initial assessment by ELISA (schemes A to D), $90 \%$ of all herds were test-negative and classified as 'green'. The remaining $10 \%$ of herds were test-positive and therefore classified as 'red'. The herd-level true prevalence decreased from $30 \%$ initially, to $29 \%$ at the time of the initial assessment in year 2, because the infection became extinct in 

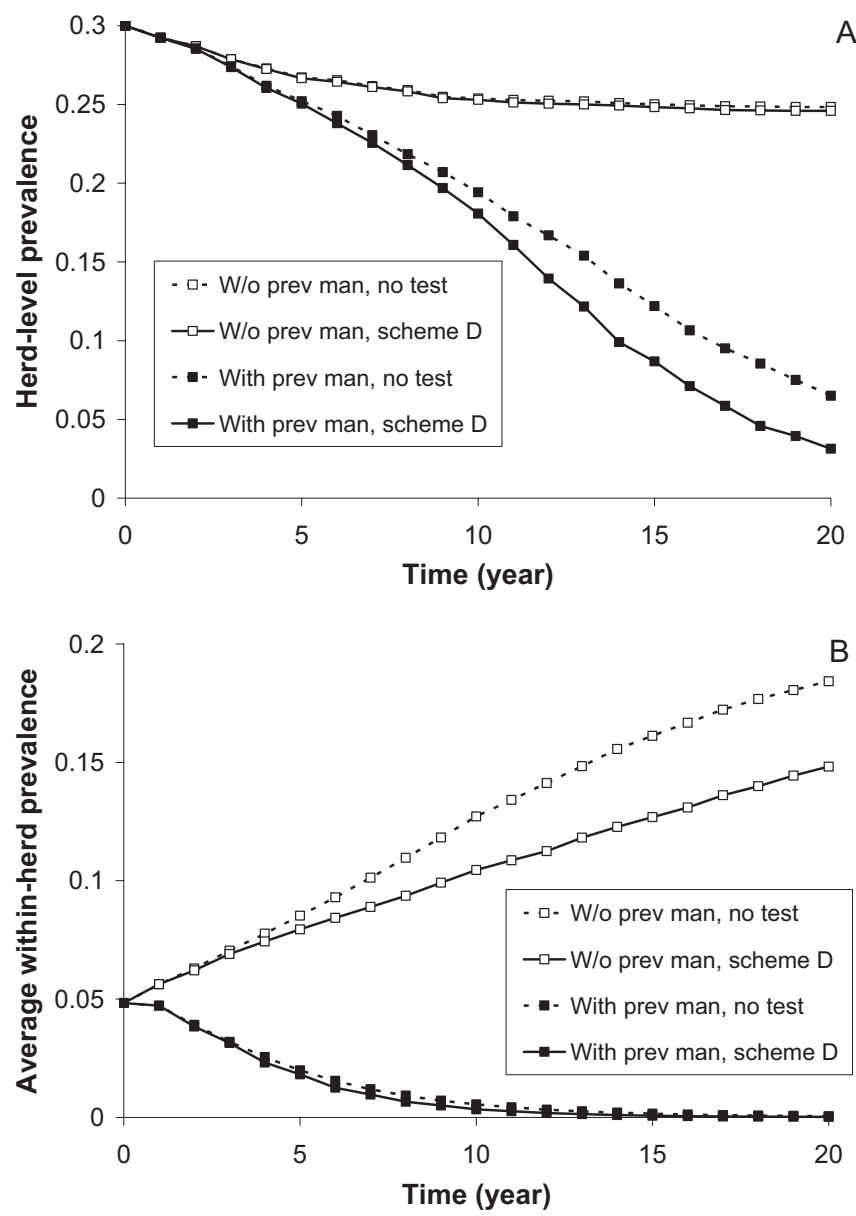

Figure 3. Estimated herd-level prevalence (A) and average within-herd prevalence (B) over time with or without (w/o) additional preventive management measures (prev man) and without testing (no test) or with test scheme D.

some herds by random processes. Therefore, $\sim 35 \%$ of the infected herds (and none of the non-infected herds) were classified as 'red' at the initial assessment. The within-herd prevalence of adult cattle in 'green' and 'red' herds at the initial assessment is shown in Figure 2A. The concomitant distribution of the concentration of Map in bulk milk is shown in Figure 2B. Immediately after the initial assessment by ELISA, 98\% of 'green' herds had a concentration of Map in bulk milk $<10^{3} / \mathrm{L}$.

At the initial assessment in scheme E, 77\% of all herds were test-negative at all five herd examinations (the first by ELISA and the second to fifth by PFC). Immediately after the end of the initial assessment (in year 6), > 99.9\% of these test-negative herds had a concentration of Map in bulk milk $<10^{3} / \mathrm{L}$.

During control in 'red' herds with schemes $\mathrm{A}$ to $\mathrm{D}$, two consecutive negative herd-examinations by IFC or six consecutive negative herd-examinations by ELISA were required to reach the same probability of $98 \%$ (see above) of having $<10^{3} \mathrm{Map} / \mathrm{L}$ of milk, irrespective of whether or not additional preventive management measures were taken. Therefore, by default, 'red' herds were 


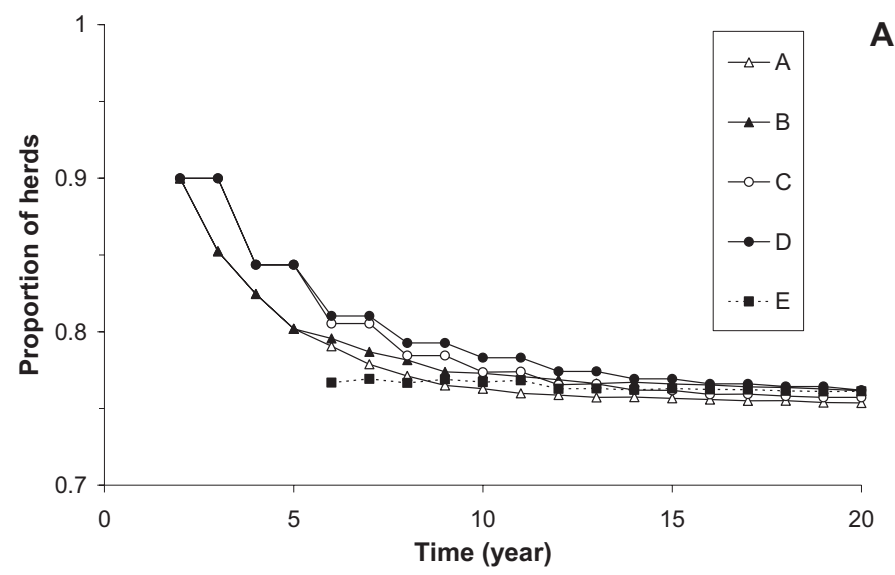

A

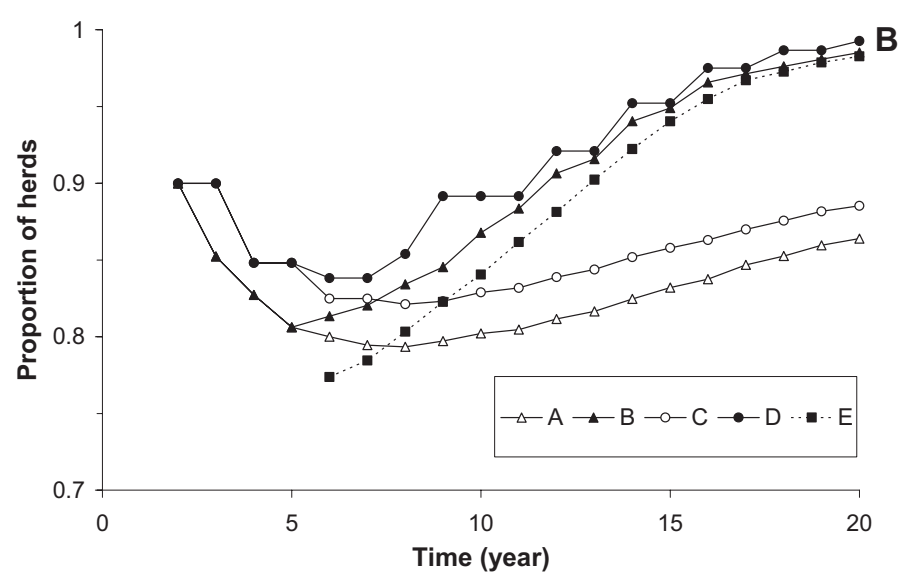

Figure 4. Proportion of herds that were classified as 'green' over time, assuming a population of closed herds with an initial herd-level true prevalence of $30 \%$ without additional preventive measures (A), and with additional preventive measures (B). Test schemes are defined in Table V.

re-classified as 'green' only after two consecutive negative herd-examinations by IFC, or six consecutive negative herd-examinations by ELISA. However, this criterion did not apply to scheme E. In scheme E, 'red' herds were assigned 'green' status only after five consecutive negative annual herd examinations (by IFC or PFC, Tab. V).

Without additional preventive management measures, the herd-level prevalence decreased towards $24-25 \%$ in year 20 while the average within-herd prevalence increased towards $10-18 \%$, depending on the test scheme. With additional preventive measures, the herdlevel prevalence decreased towards $3-7 \%$ in year 20, while the average within-herd prevalence decreased to $<0.1 \%$ (Fig. 3).

The proportion of herds classified as 'green' decreased continuously over time if no preventive measures were taken (Fig. 4A). However, if preventive management measures were taken by all participating herds, this proportion first decreased, but increased subsequently towards 86-99\%, depending on the test scheme used (Fig. 4B). Preventive measures were pivotal for 'red' herds to become 'green'. Furthermore, these measures reduced the proportion of 'green' herds that lost their status. If preventive measures were taken, culling based on IFC (schemes B, D, 
Table VI. Estimated proportion of herds with status 'green' in year 10 and 20, with various test schemes with or without additional preventive management measures taken in all herds. Test schemes are defined in Table V.

\begin{tabular}{|c|c|c|c|c|c|c|c|c|}
\hline \multirow[t]{2}{*}{ Year } & \multirow{2}{*}{$\begin{array}{l}\text { Preventive } \\
\text { management } \\
\text { measures }\end{array}$} & \multirow[t]{2}{*}{ Scheme } & \multicolumn{2}{|c|}{$\begin{array}{c}\text { Proportion 'green' herds } \\
(\%)\end{array}$} & \multicolumn{2}{|c|}{ Overall $\chi^{2}$ (4 df) } & \multicolumn{2}{|c|}{$\begin{array}{l}\text { Yates continuity-corrected } \\
\chi_{\mathrm{cc}}^{2} \text { against scheme } \mathrm{E}(1 \mathrm{df})\end{array}$} \\
\hline & & & Estimate & $95 \% \mathrm{CI}$ & $\chi^{2}$ & $P$ & $\chi^{2}$ & $P^{\mathrm{a}}$ \\
\hline \multirow[t]{10}{*}{10} & Without & $\overline{\mathrm{A}}$ & 76.3 & $75.5 ; 77.1$ & 13.9 & 0.008 & 0.5 & $>0.5$ \\
\hline & & B & 77.3 & $76.5 ; 78.1$ & & & 1.0 & $>0.5$ \\
\hline & & $\mathrm{C}$ & 77.4 & $76.5 ; 78.2$ & & & 1.2 & $>0.5$ \\
\hline & & D & 78.3 & $77.5 ; 79.1$ & & & 7.5 & 0.02 \\
\hline & & E & 76.7 & $75.9 ; 77.5$ & & & - & - \\
\hline & With & $\bar{A}$ & 80.2 & $79.4 ; 81.0$ & 387.8 & $<0.001$ & 52.7 & $<0.01$ \\
\hline & & B & 86.8 & $86.1 ; 87.4$ & & & 31.1 & $<0.01$ \\
\hline & & $\mathrm{C}$ & 82.9 & $82.2 ; 83.6$ & & & 5.1 & 0.09 \\
\hline & & D & 89.2 & $88.6 ; 89.8$ & & & 117.5 & $<0.01$ \\
\hline & & E & 84.1 & $83.3 ; 84.8$ & & & - & - \\
\hline \multirow[t]{10}{*}{20} & Without & $\bar{A}$ & 75.4 & $74.5 ; 76.2$ & 3.0 & 0.566 & - & - \\
\hline & & B & 76.2 & $75.3 ; 77.0$ & & & - & - \\
\hline & & C & 75.7 & $74.9 ; 76.5$ & & & - & - \\
\hline & & D & 76.2 & $75.4 ; 77.0$ & & & - & - \\
\hline & & E & 76.1 & $75.3 ; 76.9$ & & & - & - \\
\hline & With & $\bar{A}$ & 86.4 & $85.7 ; 87.0$ & 2957.8 & $<0.001$ & 1043.8 & $<0.01$ \\
\hline & & B & 98.5 & $98.3 ; 98.7$ & & & 2.0 & $>0.5$ \\
\hline & & $\mathrm{C}$ & 88.5 & $87.9 ; 89.1$ & & & 805.3 & $<0.01$ \\
\hline & & D & 99.3 & $99.1 ; 99.4$ & & & 42.2 & $<0.01$ \\
\hline & & E & 98.3 & $98.0 ; 98.5$ & & & - & - \\
\hline
\end{tabular}

${ }^{\text {a }}$ Bonferroni-corrected $P$.

and E) was more effective than culling based on ELISA (schemes A and C): the proportion of 'green' herds in year 20 was approximately $10 \%$ higher with culling based on IFC (Tab. VI).

With schemes A to D, the estimated average concentration of Map bacteria per litre of bulk milk in 'green' herds did not decrease below $10^{3}$ before year 8 to 15 , depending on the scheme used and whether or not additional preventive measures were taken. With scheme $\mathrm{E}$ the estimated average concentration of Map bacteria in 'green' herds was immediately and always $<10^{3} / \mathrm{L}$. However, with all schemes the distribution of the concentration of Map in milk was highly skewed, as noted before (Fig. 2). Furthermore, the proportion of 'green' herds with a high concentration of Map in milk decreased over time (Fig. 5). Therefore, with all test schemes, the proportion of 'green' herds with $<10^{3} \mathrm{Map} / \mathrm{L}$ of bulk milk increased towards $100 \%$ in year 20 . The differences in this proportion between the various test schemes with or without additional preventive management measures were small (Fig. 6).

The average cumulative discounted costs of 20-year participation in schemes A to D without additional preventive management measures ranged from $€ 13 \times 10^{3}$ to $€ 24 \times 10^{3}$ (Fig. 7A). For schemes with additional preventive measures these costs were much higher, ranging from $€ 40 \times 10^{3}$ to $€ 46 \times 10^{3}$. However, the $90 \%$ range of costs was much broader if no preventive measures were taken; therefore, for some schemes, the $95 \%$ percentile of costs were higher if no preventive measures were taken than if preventive measures were taken. The average cumulative discounted losses due to paratuberculosis up to year 20 with schemes A to D without additional preventive measures ranged from $€ 3 \times$ 


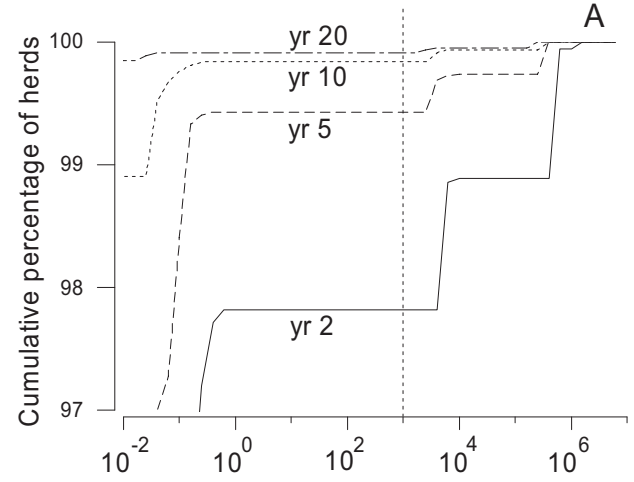

Concentration of Map organisms in milk (per litre)

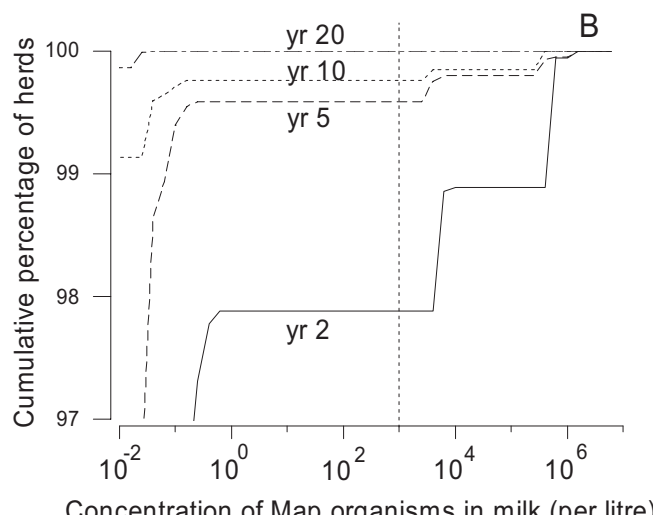

Concentration of Map organisms in milk (per litre)

Figure 5. Cumulative distribution of the concentration of Map in bulk milk from herds certified as 'green' with test scheme A without additional preventive management measures (Fig. 5A) and with additional preventive management measures (Fig. 5B). Lines indicate the cumulative distribution in years $2,5,10$, and 20 . The dashed vertical line indicates the maximum acceptable concentration. For example, approximately $98 \%$ of 'green' herds in year 2 had a concentration of Map in bulk milk $<10^{3} / \mathrm{L}$.

$10^{3}$ to $€ 7 \times 10^{3}$. Additional preventive measures reduced these losses to on average $€ 1 \times$ $10^{3}$ (Fig. 7B). When comparing the costs of various programmes, this reduction in losses due to paratuberculosis should be taken into account. Therefore, we considered the sum of the costs of participation in the programme plus losses due to paratuberculosis in Table VII. All alternative schemes were cheaper than scheme E (Tab. VII). For instance, over a 10-year period the total discounted costs of the programme plus losses due to paratuberculosis were on average $20 \%$ (with additional preventive measures) or $40 \%$ (without additional preventive measures) lower with scheme C compared to scheme E. However, over a 20-year period, the relative magnitude of the differences between schemes was smaller (Tab. VII).

\subsection{Sensitivity analyses}

If the default level of contamination of milk with Map was multiplied by $10^{6}$, the proportion of 'green' herds with $<10^{3} \mathrm{Map} / \mathrm{L}$ bulk milk was reduced from $98 \%$ to $88 \%$ in year 2. However, the effect decreased over time, and became very small beyond approximately year 10 (i.e. eight years after initial assessment, Fig. 8).

If additional preventive measures were taken with $50 \%$ reduction of effective cow-calf contacts through environmental transmission instead of $90 \%$, the proportion of herds certified as 'green' after 20 years was reduced to $92 \%$ instead of $99 \%$, compared to $76 \%$ of herds without additional preventive measures. However, the magnitude of the reduction in environmental transmission by preventive management measures had no effect on the proportion of 'green' herds with $<10^{3} \mathrm{Map} / \mathrm{L}$ bulk milk.

If the default sensitivities of both the ELISA and the IFC for each stage of the infection were multiplied by 0.75 , the proportion of 'green' herds in year 4 increased to $89 \%$ (from $84 \%$ in the default analyses). However, beyond year 10 , the differences became small. The proportion of 'green' herds with $<10^{3} \mathrm{Map} / \mathrm{L}$ bulk milk was reduced by up to $2 \%$ without preventive management measures, and up to $1 \%$ with preventive measures. Again, beyond year 10, the differences became small.

By default, two negative herd examinations by IFC were required for a 'red' herd to be re-classified as 'green'. Alternatively, only one negative herd examination by IFC was required. This increased the proportion of herds classified as 'green' in year 8 to $92 \%$ (from $85 \%$ in the default analysis), if additional preventive management measures were 

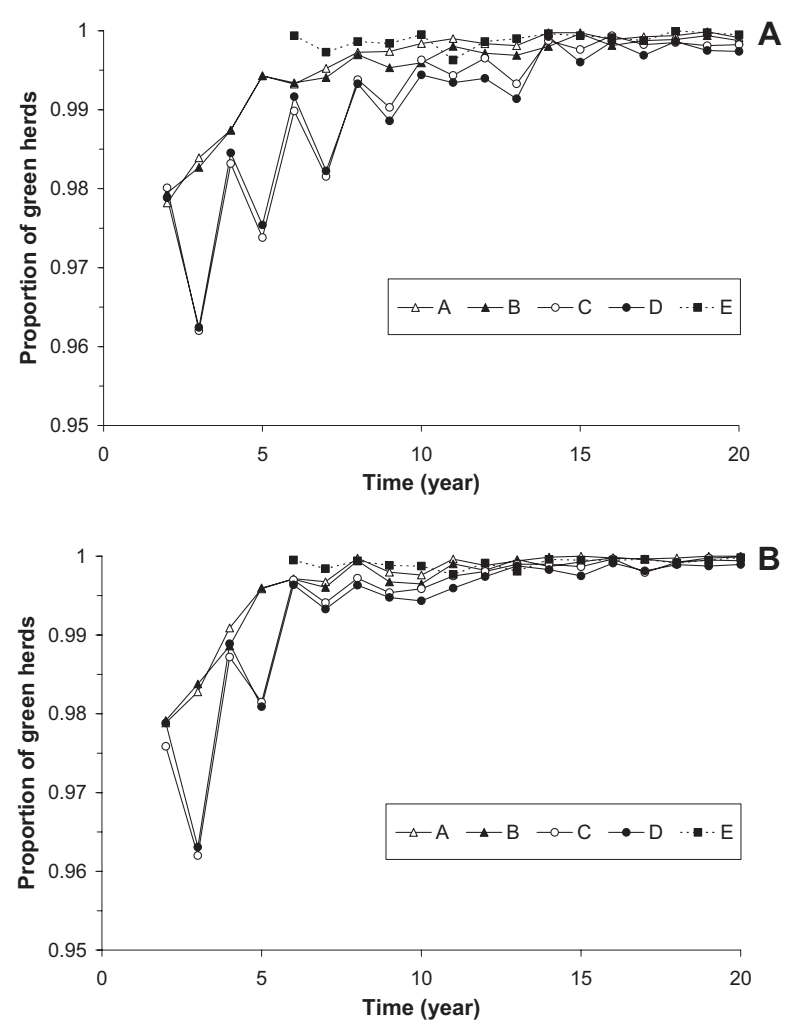

Figure 6. Proportion of 'green' herds with $<10^{3}$ Map per litre of bulk milk without additional preventive measures (A), and with additional preventive measures (B). Test schemes are defined in Table V.

taken. The reason was, of course, that 'red' herds moved to the pool of 'green' herds sooner. However, if no additional preventive measures were taken, there was only a minor increase of the proportion of 'green' herds ( $80 \%$ versus $78 \%$ in year 8 ). Moreover, beyond year 9 the differences decreased and were negligible in year $20(<0.5 \%)$. The bulk milk 'quality' of 'green' herds was slightly reduced: the percentage of 'green' herds with $<10^{3} \mathrm{Map} / \mathrm{L}$ at any point in time was reduced by up to $1 \%$ if only one negative herd examination by IFC was required instead of two. This was due to the fact that slightly more infected herds with $\geqslant 10^{3} \mathrm{Map} / \mathrm{L}$ shift to the population of 'green' herds if only one negative herd examination by IFC is required than if two negative herd examinations are required.

If the initial herd-level prevalence was 0.70 instead of 0.30, the proportion of 'green' herds in year 20 was markedly reduced to $45 \%$ without additional preventive management measures and to $76 \%$ with additional preventive measures. The proportion of 'green' herds with $<10^{3}$ Map per litre of bulk milk during the first years of the simulations was decreased by up to $7 \%$, but this decrease was small beyond year 10 . The average cumulative discounted costs up to year 20 increased by $€ 13 \times 10^{3}$ without additional preventive management measures, but only by $€ 3 \times 10^{3}$ with additional preventive measures.

\section{DISCUSSION}

To our knowledge, this is the first modelling study of a bulk milk quality assurance programme for paratuberculosis in dairy herds. The results indicate that the simulated programmes effectively guarantee the bulk milk 


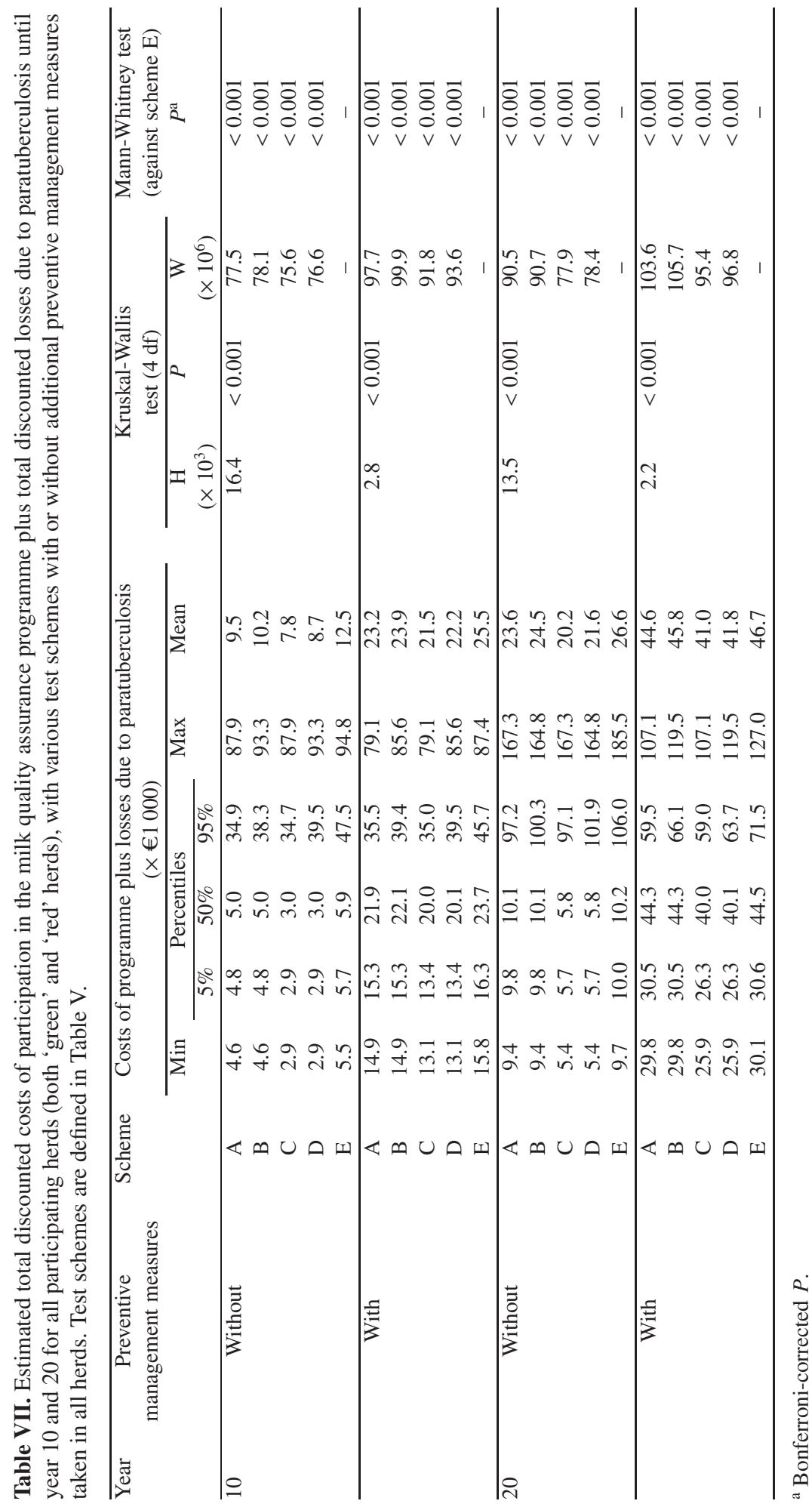



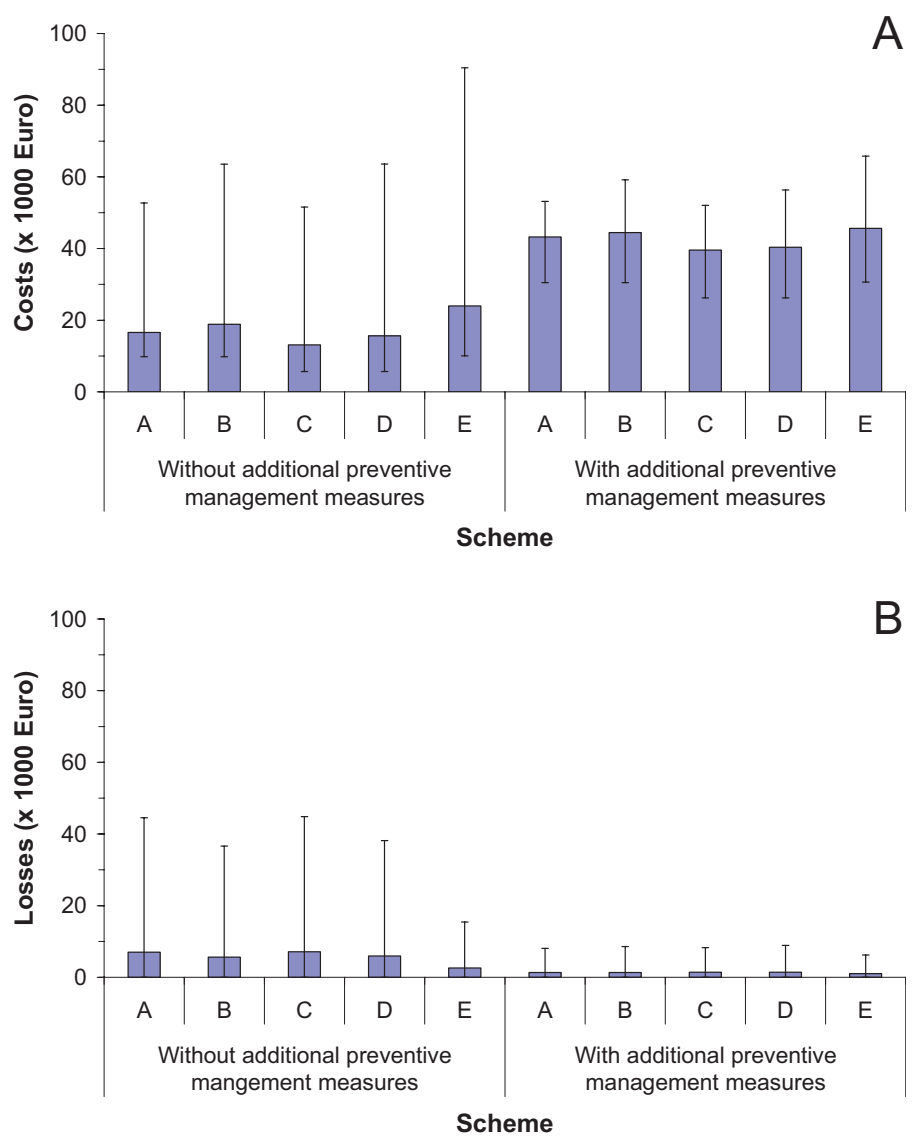

Figure 7. Mean cumulative discounted costs of participation in a bulk milk quality assurance programme (A) and losses due to paratuberculosis (B) per herd up to year 20 (averaged over all 'green' and 'red' herds). Bars indicate the 5\% to 95\% range. Test schemes are defined in Table V.

quality of 'low-Map bulk milk' herds, called 'green' herds in our simulations.

The results of this study show that test schemes A to D (milk quality assurance), were considerably cheaper than scheme $\mathrm{E}$ (the 'Map-free' certification-and-surveillance programme) during the first ten years of participation - which is a time frame that is likely to strongly influence farmers' decisions to enter a programme. Moreover, with the simulated test schemes for a bulk milk quality assurance programme, a test-negative herd reaches the desired status in one herd-examination at the initial assessment, as opposed to five herdexaminations in the 'Map-free' certificationand-surveillance programme in the Nether- lands [4]. These are attractive assets of the new bulk milk quality assurance programmes. However, incentives such as a milk price differentiation are still needed for farmers to justify the costs of participation ${ }^{11}$.

Key elements in a successful bulk milk quality assurance programme are preventive measures to reduce the risk of introduction of Map in participating herds (including trade

\footnotetext{
${ }^{11}$ Velthuis A.G.J., Weber M.F., de Koeijer A.A., van Roermund H.J.W., Milk-quality-assurance program for Johne's disease: decision analysis from a farmers perspective, in: Proc. 11th Int. Symposium on Vet. Epidemiology and Economics, Cairns, 2006, p. 313.
} 


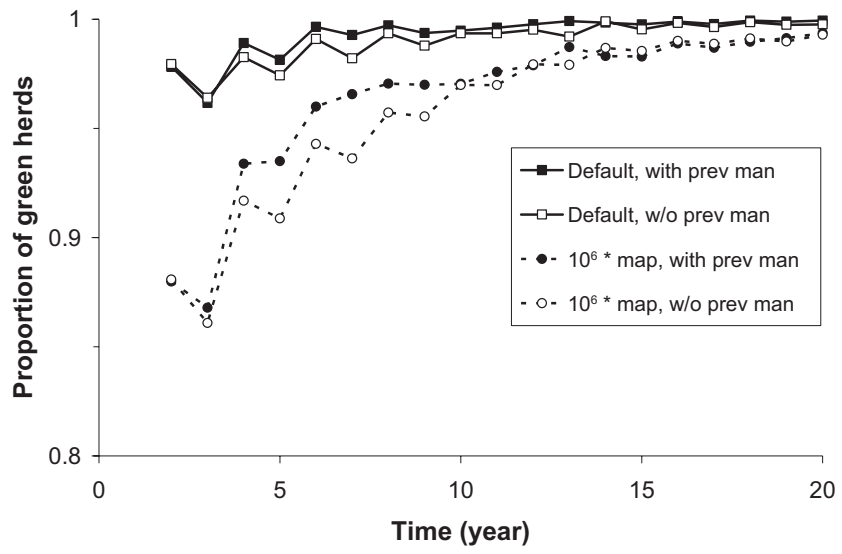

Figure 8. Proportion of 'green' herds with $<10^{3}$ Map per litre, using test scheme D, with or without (w/o) preventive management measures (prev man), and with different assumptions on the concentrations of Map bacteria in milk. The default concentrations of Map in milk are given in Table IV. Alternatively, these concentrations were multiplied by $10^{6}$ in the sensitivity analyses for this parameter.

restrictions), preventive management measures to reduce within-herd spread of Map, and the initial assessment, surveillance, and control procedures. The present study was restricted to closed herds. The effects of animal trade were analysed separately using a mathematical model ${ }^{12}$. In the present study, additional preventive management measures to reduce within-herd spread of Map were found to have a major effect on the proportion of herds that can be certified as 'low-Map bulk milk' (i.e. 'green' in this study). These management measures were pivotal for test-positive ('red') herds to become certified as 'low-Map bulk milk' ('green'). This is, of course, related to the assumptions made on the effectiveness of management measures in reducing Map transmission. However, as expected, management measures only had a minor effect on the bulk milk quality of 'low-Map bulk milk' herds ('green') - since the majority of these herds were truly uninfected.

\footnotetext{
${ }^{12}$ Van Roermund H.J.W., Weber M.F., de Koeijer A.A., Velthuis A.G.J., de Jong M.C.M., Development of a milk quality assurance program for paratuberculosis: from within and between herd dynamics to economic decision analysis, in: Manning E.J.B., Nielsen S.S. (Eds.), Proc. 8th Int. Coll. Paratuberculosis, Copenhagen, 2005, pp. 51-59.
}

We simulated initial assessment-, surveillance-, and control-procedures based on tests at the animal-level (ELISA, faecal culture). Preferably, these procedures would be based on quantification of the concentration of Map organisms in bulk milk. Techniques to routinely quantify Map in large numbers of bulk milk samples might become available (for instance, see [25]) but have not yet been validated for use in the Dutch dairy population. However, our results showed that herd examinations by ELISA for the initial assessment and surveillance procedures effectively ensure the quality of 'low-Map bulk milk': $>96 \%$ of simulated certified herds (increasing to $>99 \%$ after 10 years) were below $10^{3} \mathrm{Map} / \mathrm{L}$. Surveillance by biennial herd examinations by ELISA was sufficient and resulted in the lowest costs to participants. However, control in 'red' herds by culling of test-positive animals and their last-born offspring based on biennial IFC was more effective than culling based on annual ELISA. Therefore, a programme including initial assessment by herd examination by ELISA, surveillance by biennial herd examinations by ELISA, and control in infected herds by biennial herd examinations by IFC (i.e. test scheme D) is the most attractive programme, according to the simulations. 
In the face of uncertainty and lack of information, important assumptions were made in the present study. However, the assumptions considered to be the most critical were studied in our sensitivity analyses. Due to deficiencies in the current methodology, it has so far been impossible to accurately quantify Map organisms in milk from a dairy herd with paratuberculosis [7, 14]. For instance, colony forming units can not simply be translated to concentrations of Map organisms, because of clumping of Map in specimens and insensitivity of culture. Our sensitivity analyses showed that a $10^{6}$ fold increase in the assumed concentration of Map in milk from infected animals would initially decrease the number of certified 'low-Map bulk milk' ('green') herds with $<10^{3} \mathrm{Map} / \mathrm{L}$ by $10 \%$. However, such high concentrations of Map in milk are probably not biologically plausible, even in so called 'super shedders'. Even so, the effects of such an increase in the concentration of Map in milk from infected animals on the bulk milk quality of 'green' herds were very small beyond year 10 (i.e. eight years after the initial assessment procedure). Due to the uncertainty and lack of quantitative information on the probability of human disease due to exposure to Map, no target confidence for 'low-Map bulk milk' herds to be below $10^{3} \mathrm{Map} / \mathrm{L}$ could be defined prior to this study. However, the results show that, over time, this confidence approximates to $100 \%$ with all simulated test schemes.

In this study, comparisons between simulated test schemes were supported by formal statistical testing. However, with increasing numbers of iterations in a stochastic simulation, small and irrelevant differences between schemes can become statistically significant. Therefore, comparisons between schemes need to be focussed on the practical relevance of differences, rather than on statistical significance alone.

Based on the results of this and other ${ }^{11,12}$ studies, a new quality assurance programme for paratuberculosis in Dutch dairy herds has been initiated in January 2006. The new programme is run in addition to the pre-existing certification-and-surveillance programme for 'Map-free' herds [4, 8, 37]. In the new pro- gramme, farmers may choose freely between test schemes C and D (Tab. V). Furthermore, farmers may choose to replace serological herd examinations with herd examinations by milk-ELISA, including all lactating cattle in the herd. The results of the new quality assurance programme will be studied when they become available over time.

This study was performed to assist decision-makers in selecting suitable alternatives for a bulk milk quality assurance programme. A number of assumptions related specifically to Dutch dairy herds (such as the relative abundance of management risk-profiles, costs and initial prevalence). However, the aim of the study, which is to develop a programme to improve bulk milk quality by reducing the contamination with $M a p$, is of global interest. Furthermore, the mechanisms of paratuberculosis infection, disease, and testing are comparable in other dairy cattle populations around the globe. Therefore, the concepts of this study equally apply to other countries.

It is concluded that a bulk milk quality assurance programme for paratuberculosis in closed dairy herds is feasible. Serology is sufficient for initial assessment and surveillance in the programme to warrant bulk milk quality. However, for control in test-positive herds, culling based on faecal culture is more effective than culling based on ELISA. Preventive management measures only had a minor effect on the bulk milk quality of 'low-Map bulk milk' herds, but may increase the probability of obtaining this status. The present study provided decision-makers with information on the cost-effectiveness of different programmes.

Acknowledgements. This study was funded by the Dutch Ministry of Agriculture, Nature and Food Quality and the Dutch Dairy Board. The authors thank the steering committee of the Paratuberculosis Programme Netherlands for interesting discussions on the subject, and Peter Franken, Huybert Groenendaal, Gerdien van Schaik, Mart de Jong, and Koos Verhoeff for their advice and support during this study.

Declaration of interest. The principal author (MFW) is employed by the Animal Health Service, which is running a quality assurance programme for paratuberculosis, partially based on the results of this study. 


\section{REFERENCES}

[1] Altman D.G., Practical statistics for medical research, Chapman and Hall, London, UK, 1999.

[2] Animal Sciences Group, Quantitative information on livestock 2003-2004, 2003, 441 p.

[3] Ayele W.Y., Svastova P., Roubal P., Bartos M., Pavlik I., Mycobacterium avium subspecies paratuberculosis cultured from locally and commercially pasteurized cow's milk in the Czech Republic, Appl. Environ. Microbiol. (2005) 71:1210-1214.

[4] Benedictus G., Verhoeff J., Schukken Y.H., Hesselink J.W., Dutch paratuberculosis programme history, principles and development, Vet. Microbiol. (2000) 77:399-413

[5] Chacon O., Bermudeze L.E., Barletta R.G., Johne's disease, inflammatory bowel disease, and Mycobacterium paratuberculosis, Annu. Rev. Microbiol. (2004) 58:329-363.

[6] Chiodini R.J., Van Kruiningen H.J., Merkal R.S., Ruminant paratuberculosis (Johne's disease): the current status and future prospects, Cornell Vet. (1984) $74: 218-262$

[7] Dundee L., Grant I.R., Ball H.J., Rowe M.T., Comparative evaluation of four decontamination protocols for the isolation of Mycobacterium avium subsp. paratuberculosis from milk, Lett. Appl. Microbiol. (2001) 33:173-177.

[8] Ezanno P., van Schaik G., Weber M.F., Heesterbeek J.A., A modeling study on the sustainability of a certification-and-monitoring program for paratuberculosis in cattle, Vet. Res. (2005) 36:811-826.

[9] Gao A., Mutharia L., Chen S., Rahn K., Odumeru J., Effect of pasteurization on survival of Mycobacterium paratuberculosis in milk, J. Dairy Sci. (2002) 85:3198-3205.

[10] Giese S.B., Ahrens P., Detection of Mycobacterium avium subsp. paratuberculosis in milk from clinically affected cows by PCR and culture, Vet. Microbiol. (2000) 77:291-297.

[11] van der Giessen J.W.B., Haring R.M., Vauclare E., Eger A., Haagsma J., van der Zeijst B.A.M., Evaluation of the abilities of three diagnostic tests based on the polymerase chain reaction to detect Mycobacterium paratuberculosis in cattle; their application in a control program, J. Clin. Microbiol. (1992) 30:1216-1219.

[12] Grant I.R., Ball H.J., Neill S.D., Rowe M.T., Inactivation of Mycobacterium paratuberculosis in cows' milk at pasteurization temperatures, Appl. Environ. Microbiol. (1996) 62:631-636.

[13] Grant I.R., Ball H.J., Rowe M.T., Effect of higher pasteurization temperatures, and longer holding times at $72^{\circ} \mathrm{C}$, on the inactivation of Mycobacterium paratuberculosis in milk, Lett. Appl. Microbiol. (1999) 28:461-465.
[14] Grant I.R., Hitchings E.I., McCartney A., Ferguson F., Rowe M.T., Effect of commercial-scale high-temperature, short-time pasteurization on the viability of Mycobacterium paratuberculosis in naturally infected cow's milk, Appl. Environ. Microbiol. (2002) 68:602-607.

[15] Grant I.R., Ball H.J., Rowe M.T., Incidence of Mycobacterium paratuberculosis in bulk raw and commercially pasteurized cow's milk from approved dairy processing establishments in the United Kingdom, Appl. Environ. Microbiol. (2002) 68:2428-35.

[16] Grant I.R., Williams A.G., Rowe M.T, Muir D.D., Efficacy of various pasteurization time-temperature conditions in combination with homogenization on inactivation of Mycobacterium avium subsp. paratuberculosis in milk, Appl. Environ. Microbiol. (2005) $71: 2853-2861$

[17] Groenendaal H., Nielen M., Jalvingh A.W., Horst S.H., Galligan D.T., Hesselink J.W., A simulation of Johne's disease control, Prev. Vet. Med. (2002) 54:225-245.

[18] Groenendaal H., Galligan D.T., Mulder H.A., An economic spreadsheet model to determine optimal breeding and replacement decisions for dairy cattle, J. Dairy Sci. (2004) 87:2146-57.

[19] Houben E.H.P., Huirne R.B.M., Dijkhuizen A.A., Kristensen A.R., Optimal replacement of mastitic cows determined by a hierarchic Markov process, J. Dairy Sci. (1994) 77:2975-2993.

[20] Jubb T., Galvin J., Herd testing to control bovine Johne's disease, Vet Microbiol. (2000) 77:423-428.

[21] Kalis C.H.J., Hesselink J.W., Russchen E.W., Barkema H.W., Collins M.T., Visser I.J., Factors influencing the isolation of Mycobacterium avium subsp. paratuberculosis from bovine fecal samples, J. Vet. Diagn. Invest. (1999) 11:345-351.

[22] Kalis C.H.J., Hesselink J.W., Barkema H.W., Collins M.T., Culture of strategically pooled bovine fecal samples as a method to screen herds for paratuberculosis, J. Vet. Diagn. Invest. (2000) 12:547-551.

[23] Kennedy D.J., Allworth M.B., Progress in national control and assurance programs for bovine Johne's disease in Australia, Vet. Microbiol. (2000) 77:443-51.

[24] McDonald W.L., O'Riley K.J., Schroen C.J., Condron R.J., Heat inactivation of Mycobacterium avium subsp. paratuberculosis in milk, Appl Environ. Microbiol. (2005) 71:1785-1789.

[25] Metzger-Boddien C., Khaschabi D., Schonbauer M., Boddien S., Schlederer T., Kehle J., Automated high-throughput immunomagnetic separation-PCR for detection of Mycobacterium avium subsp. paratuberculosis in bovine milk, Int. J. Food Microbiol. (2006) 110:201-208. 
[26] Muskens J., Barkema H.W., Russchen E., van Maanen K., Schukken Y.H., Bakker D., Prevalence and regional distribution of paratuberculosis in dairy herds in The Netherlands, Vet. Microbiol. (2000) 77:253261.

[27] Nauta M.J., van der Giessen J.W.B., Human exposure to Mycobacterium paratuberculosis via pasteurised milk: a modelling approach, Vet. Rec. (1998) 143:293-296.

[28] O'Reilly C.E., O'Connor L., Anderson W., Harvey P., Grant I.R., Donaghy J., Rowe M., O'Mahony P., Surveillance of bulk raw and commercially pasteurized cows' milk from approved Irish liquid-milk pasteurization plants to determine the incidence of Mycobacterium paratuberculosis, Appl. Environ. Microbiol. (2004) 70:5138-5144.

[29] Pearce L.E., Truong H.T., Crawford R.A., Yates G.F., Cavaignac S., de Lisle G.W., Effect of turbulentflow pasteurization on survival of Mycobacterium avium subsp. paratuberculosis added to raw milk, Appl. Environ. Microbiol. (2001) 67:3964-3969.

[30] Rademaker J.L., Vissers M.M., Te Giffel M.C., Effective heat inactivation of Mycobacterium avium subsp. paratuberculosis in raw milk contaminated with naturally infected feces, Appl. Environ. Microbiol. (2007) 73:4185-90.

[31] van Schaik G., Schukken Y.H., Crainiceanu C., Muskens J., VanLeeuwen J.A., Prevalence estimates for paratuberculosis adjusted for test variability using Bayesian analysis, Prev. Vet. Med. (2003) 60:281-295.

[32] Stadhouders J., Jørgensen K., Prevention of the contamination of raw milk by a hygienic milk production, in: International Dairy Federation, Bulletin IDF 251 , Detection and prevention of anaerobic spore formers and cheese quality, Brussels, 1990, pp. 32-36.

[33] Streeter R.N., Hoffsis G.F., Bech-Nielsen S., Shulaw W.P., Rings D.M., Isolation of Mycobacterium paratuberculosis from colostrum and milk of subclinically infected cows, Am. J. Vet. Res. (1995) 56:13221324.

[34] Sung N., Collins M.T., Thermal tolerance of Mycobacterium paratuberculosis, Appl. Environ. Microbiol. (1998) 64:999-1005.

[35] Sweeney R.J., Whitlock R.H., Hamir A.N., Rosenberger A.E., Isolation of Mycobacterium paratuberculosis after oral inoculation in uninfected cattle, Am. J. Vet. Res. (1992) 53:1312-1314.

[36] Sweeney R.W., Whitlock R.H., Rosenberger A.E., Mycobacterium paratuberculosis cultured from milk and supramammary lymph nodes of infected asymptomatic cows, J. Clin. Microbiol. (1992) 30:166-71.

[37] Weber M.F., Groenendaal H., van Roermund H.J.W., Nielen M., Simulation of alternatives for the Dutch Johne's disease certification-and-monitoring program, Prev. Vet. Med. (2004) 62:1-17. 